\title{
AC 2008-926: A GUIDED TOUR OF THE FUTURE OF EDUCATION
}

\section{Eugene Rutz, University of Cincinnati}

Eugene is an Academic Director in the College of Engineering at the University of Cincinnati. He manages the College's accelerated engineering degree programs as well as a pre-engineering program with local high schools. Eugene also helps faculty in the use of instructional technology. He is a self-described "hopeful skeptic" concerning learning in virtual worlds.

\section{Chris Collins, University of Cincinnati}

Chris Collins is an IT Analyst in the UCit Instructional \& Research Computing department at the University of Cincinnati. Chris specializes in developing supportable, sustainable enterprise services that integrate emerging technologies into existing and future curricula for distance learning, hybrid, and traditional courses, including the introduction of an online course management system, podcasting, use of wikis and blogs in education, and virtual world technologies. She currently manages the campus-wide podcasting and Second Life projects at the University of Cincinnati, and serves as the Second Life Ambassador for the Ohio Learning Network, a consortium of 80 colleges and universities in Ohio.

\section{Mani Mina, Iowa State University}

Mani Mina (SM'98) received the B.S. degree, the M.S. degree in physics, and the M.S. and Ph.D. degrees in electrical engineering from Iowa State University, Ames, in 1982, 1985, 1987, and 1989, respectively. H e has research experience in applied electromagnetics, microelectronics and device physics, nondestructive evaluation, instrumentation, networking and physical layer issues. $\mathrm{He}$ is also engaged in research on pedagogical aspect of technology and engineering education. 


\section{A Guided Tour of the Future of Education}

\section{Introduction}

As an instructor have you ever found your self exasperated by students who sit passively in class despite your best efforts at engaging them? From the other side of the desk, there are enumerable students desperately wishing the instructor would find a way to teach that wasn't just lecture with PowerPoint or equations on a white board. If a classroom existed that required active participation of all students and instructors and there was immediate and meaningful feedback based on the students' ability to demonstrate what was learned, would you use it?

Not today and not next year, but during the professional career of most of today's educators, this classroom will exist. A prototype of this environment exists and is being used by millions of students and a growing number of educators. Actually it is not one prototype but several that go under the names of wikis, social networks, and virtual environments.

\section{Wiki}

A wiki is a piece of software that resides on a server and permits individuals to create and edit content of web pages using a web browser. They support hyperlinks and generally incorporate a simple mechanism for creating new pages and links between internal pages. In addition to adding and modifying content, individuals may also be able to change the organization of the content. The first wiki - wikiwikiweb - was developed by Ward Cunningham in 1994. (1)

The key value of a wiki is that multiple users can easily add, edit, and amend a collective pool of knowledge, all while preserving a record of how, when, and by whom the information was added. This "history" mechanism of the wiki page allows the co-authors to analyze and debate revisions, revert to previous versions, and provide a measure of accountability and/or achievement by identifying each contributor to the knowledge base. Many wikis also allow the incorporation of various kinds of media, including images, graphs, and audio/video content, that allow for the development of media rich content repositories. Perhaps the best known application of a wiki is the Wikipedia project, "the free encyclopedia that anyone can edit" (2), but wikis are also being used by businesses for knowledge management, by researchers to document progress and findings, and by educators to allow for collaborative creation of content.

\section{Virtual Environments}

Characteristics often attributed to virtual environments include (adapted from Dillenbourg (3)):

- The information space has been specifically designed and includes an explicit representation

- Interactions occur in the information space

- Users of the information space are able to construct elements of that space

These characteristics transform an information space into an environment that facilitates interaction and creation of content.

An important subset of virtual environments are referred to as MUVEs, multi-user virtual environments. These typically support three dimensional graphics, allow for many simultaneous 
users and are persistent. Persistent refers to the characteristic that the environment is available at all times and that it can be modified and developed even while users are not participating in that environment.

\section{Social Networks}

As regards use of the web, a social network is a web site that allows a user to create a profile and construct linkages to others who also use the site. Individuals not directly linked to a user can become linked through mutual connections. A social network website allows users to see the common connections they have among individuals they know and those they do not (see www.commoncraft.com/video-social-networking for a clever video on this concept).

Social networking sites have grown substantially in recent years to include tens of millions of users, more than half of whom are teenagers. According to a PEW study (4) more than half of youths ages 12-17 who are active on the web use social networking sites. The study also reports that older teens, especially girls, are likely to use these sites, and on sites that allow the users to create or add their own content (pictures, graphics, music), girls continue to dominate most elements of content creation. Some $35 \%$ of all teen girls blog, compared with $20 \%$ of online boys, and $54 \%$ of wired girls post photos online compared with $40 \%$ of online boys (4).

\section{Learning Should Be...}

While good classroom teaching is highly effective and can incorporate all of the following points, the future immersive virtual "classroom" will include these attributes:

\section{Engaging}

It's pretty simple really; students will spend more time on a topic that is interesting to them than one that is not. For most students, a traditional classroom lecture is not an engaging experience, even if the topic is one they want to learn and the instructor is effective. Teach the same topic in a lab setting, in the field, or with individuals affected by the topic present, and the engagement of students will (generally) increase significantly. Until the folks at NASA come up with a reliable

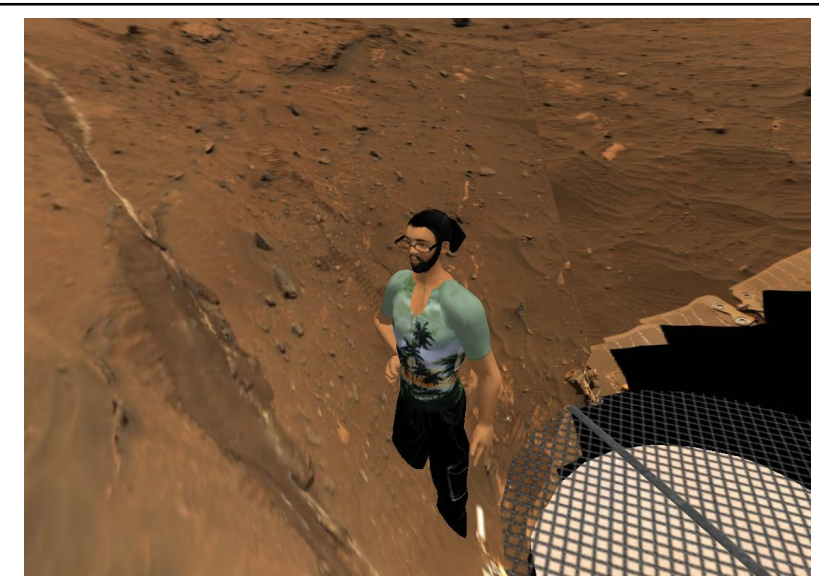

Figure 1 Victoria Crater on Mars working transporter, the opportunities for frequent out-of-classroom experiences will be small.

A virtual world removes the limitations of place. Individuals or an entire class can travel to the UN, stand on the Martian terrain, or meet face-to-face with energy policy makers. A virtual world can also remove the limitation of time. In this environment you can visit a WWII battlefield or practice chemistry with the Curies. I hear the hanging gardens of Babylon are beautiful this time of year.

Visually Appealing 
We've been told for years that most college-age students are visual learners $(5,6)$ and the education community has begun to use technology effectively to facilitate this learning style. More and more of the traditional classrooms are being changed into "electronic classrooms" that permit projection of images, multi-media and computer animations. That's nice but it falls short of an immersive visually appealing environment.

Is the "holodeck" portrayed on Star Trek beyond my life time? Maybe so - but some say it will be here before 2020. In virtual worlds avatars reside in a three dimensional environments that can be visually rich - and not just gardens and seaside locations. Examining a life-size model of the lunar lander is more appealing than a picture. Sitting in the eye of a hurricane is not only interesting but just can't be done outside of Oz.

Active

We've also been told for years that many students are active learners and a growing number of educators are developing content and lessons that incorporate movement or the necessity of making a choice and acting on that choice. Flash animations that require a student to manipulate a variable then examine the consequences of that choice are a somewhat common example.

Wikis require users to supply the content and to hopefully review and "police" the content for accuracy. Rather than writing a paper in isolation that is ultimately seen only by the instructor, students can collaboratively engage in creating the evidence of their learning and benefit from peer-review of their work In the example of Wikipedia, a class assignment to rigorously examine and if necessary update a specific encyclopedia entry that relates to the course material can provide a unique and interactive learning experience for students that engages a global audience of reviewers and commentators. Frequent contributors to Wikipedia refer to the sense of empowerment that it gives them, a sense that they are contributing to something meaningful (7) - this sense is sorely lacking in many modern classrooms.

In a virtual world, users also supply the content but the content is not restricted to words or flat images. The environment itself is created by the users. The environment can be part of the content, it can facilitate the content or it can distract from the content. In Piaget's terms (8) knowledge is an interaction between subject and object. Nowhere is the interaction between object and student more "real" than in a virtual world. Not only can I create the trebuchet to visualize equations of motion, I can launch myself in it and watch the ground rise up to meet me. Continuing with the constructivist thought of education, the instructor is responsible for facilitating an environment in which each student is responsible for creating and exploring the knowledge created in that environment (9).

\section{Socially Connected}

One answer to the issue of the lack of women in engineering is that, real or perceived, engineering is a profession for intelligent, serious, unexciting individuals who tend to be indifferent to human relations and cultural norms (10). The image of engineering as a technical activity divorced from social activity discourages women from pursuing engineering (11), but that may change if girls begin to translate their use of existing web-based social networks and content creation software into a desire to invent new technology (12). 
Indeed, co-op programs and service learning initiatives are in part a recognition that students benefit from an education that is socially connected. Virtual internships with technology companies (13), manufacturing, and other industries may provide students with the ability to build professional networks that are not limited by geography, or participate in volunteer and charity activities in virtual environments that resonate with their own personal interests. To date, most virtual worlds fail to meet this need but it will not always be so. Money (real dollars) has been raised within a Second Life "Relay for Life" event and as more users (probably women) become engaged in virtual environments and help to build that environment, this will improve. It is also not hard to imagine the blending of a social network environment with a virtual immersive environment.

\section{Where Are We Headed}

\section{Sociology, Group Dynamics, Governance}

With real and changing populations, virtual environments provide an excellent opportunity to explore various forms of interaction, community building and governance. Students can explore various forms of teams and group leadership, they can engage in political action and they can observe an array of human behavior without many of the risks associated with taking action in the real world. In terms of social science, researchers have long sought to measure minute variations in social behavior, and the use of web-based and virtual world technologies provide reams of data for further analysis, as well as the ability to manipulate variables in perfectly controlled environments. Tomorrow's students will have the opportunity to conduct research in ways that have never been possible before using these new technology tools.

\section{Business and Economics}

Virtual worlds have a real economy and currency exchange, buyers and sellers of both real world goods and services as well as virtual goods and services are developing, and individual from developing nations are gaining increased access to global markets through web-based and virtual world technologies. Any student or group of students can set up a business making it possible to experiment with marketing, pricing, organization and markets. Economic theories can be implemented and evaluated in a meaningful way.

\section{Product Development}

Engineers, architects, artists and others can create not only objects but buildings and systems. The virtual environment allows objects and systems to have attributes and functions (the plane can fly) such that the consequences of design can be studied and design alternatives evaluated. This evaluation can include not only the technical aspects of the design but the social implications and potential customer reaction and use of the product.

\section{Training}

Virtual environments facilitate active learning for groups as diverse as:

- First responders

- Medical personnel

- Journalists

- Laboratory workers 
Emergency personnel are already using virtual worlds to prepare for potential emergency situations (14). While obviously not affecting real individuals, the participants can be faced with situations that are unknown, evolving, and impacted by the public. The level of complexity is greater than can be accomplished otherwise and the ability to observe consequences of action or inaction is greater.

\section{Collaboration}

Teams of students or researchers or business partners can use virtual environments as meeting places to exchange ideas, explore possibilities, and build a shared vision with a powerful sense of place. Rather than simply imagining or using flat representation of a concept, the team can share three dimensional versions of objects or tools or systems created in this virtual environment.

Within the virtual environments ideas can be rendered into meaningful representations to evaluate alternatives from both a performance point of view and an aesthetic one. NASA is in the process of developing their capacity in virtual worlds to achieve a level of collaboration and exploration than has not been possible before. (15)

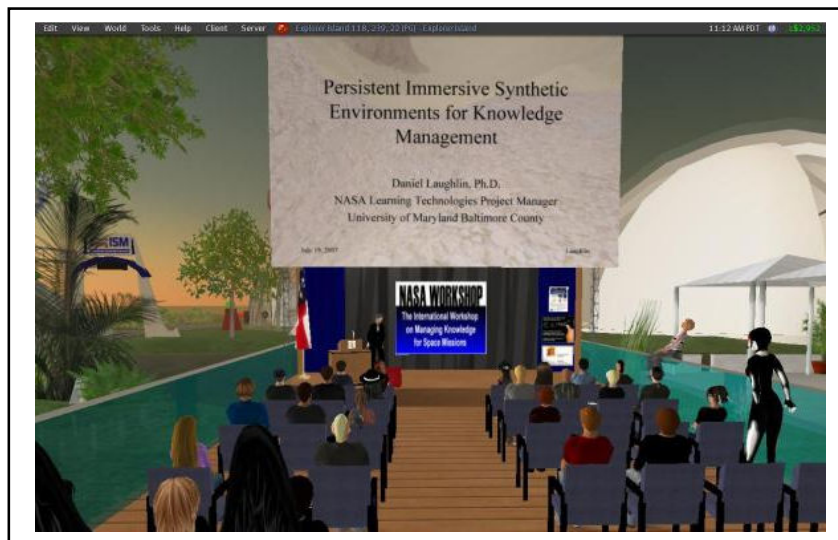

Figure 2 Collaboration within NASA

\section{Student Centered}

One significant factor in providing student centered education is the accessibility of content and experiences at the students' convenience, not the instructors. While web pages provide one such possibility, they do not provide the robustness of experience or the engagement of virtual worlds. A classroom, office, museum, even an entire ecosystem can be available for information and exploration any time day or night.

The Centers of Disease Control has for example created a presence in Second Life to provide one such opportunity for individuals to gain information and explore topics (16). CDC can collect data about the topics individuals are most interested in, the length of time spent on a topic, and potentially how individuals use the information.

\section{It's Coming}

Jennings and Collins (17) provide a snapshot of where these environments are heading. With over 150 accredited academic institutions and possibly 40 million Americans participating in virtual worlds, it is not a passing fad. As institutions and educators gain experience and proficiency in these settings, the amount and quality of content and experiences will increase dramatically.

What remains to be seen is how pedagogy will change with both the technology and students (and educators) interaction with the technology. With expectations of collaborative content creation (wikis) and socially inclusive activities growing among young people it is hard to see 
how the traditional educational environment can, as it is today, accommodate students' expectations and prepare them to succeed in this real world.

\section{Bibliography}

1. Matais, N. 2003. What is a Wiki. SitePoint. www.sitepoint.com/article/what-is-a-wiki

2. Wikipedia, The Free Encyclopedia. 2008. Available at: http://en.wikipedia.org/wiki/Main_Page. Accessed February 23, 2008.

3. Dillenbourg, P. 2000. Virtual Learning Environments. EUN Conference 2000: Learning In The New Millennium: Building New Education Strategies For Schools http://tecfa.unige.ch/tecfa/publicat/dil-papers2/Dil.7.5.18.pdf

4. Lenhart, A and Madden, M. 2007 Social Networking Websites and Teens: An Overview, Pew Internet \& American Life Project. www.pewinternet.org/PPF/r/198/report_display.asp

5. Felder, Richard; Silverman, L. 1988. Learning and Teaching Styles in Engineering Education. Engr. Education, 78(7) pp. 674-681

6. Barbe, W. and Milone, M. 1981. What We Know About Modality Strengths. Educational Leadership. Pp. 378-380.

7. Jenkins, Henry. 2008. What Wikipedia Can Teach Us About the New Media Literacies. Available at: http://www.educause.edu/Program/13300?PRODUCT_CODE=ELI081/GS01 Accessed February 23, 2008.

8. Bringuier, J.C. 1980. Conversations with Jean Piaget. The University of Chicago Press.

9. Holzer, S.M. 1994. From Constructivism to Active Learning. The Innovator No. 2. www.succeed.ufl.edu/innovators/innovator_2/innovator002.html

10. Florman, S. 1976 The Existential Pleasures of Engineering. New York, NY St Martins Press.

11. Beder, S. 1989. Towards a More Representative Engineering Education. International Journal of Applied Engineering Education. Vol. 5, no. 2.

12. Rosenbloom, S. "Sorry, Boys, This Is Our Domain." The New York Times. February 21, 2008. Available at: http://www.nytimes.com/2008/02/21/fashion/21 webgirls.html?pagewanted=1\&_r=2 Accessed on February 23, 2008.

13. Jobs at IBM. 2008. Internship in Social Computing Research. Available at: http://careers.peopleclick.com/jobposts/Client40_GLDTR/BU1/External/139-26959.htm?lid=DEA Accessed on: February 23, 2008.

14. Idaho Bioterrorism Awareness and Preparedness Program. 2007. University of Idaho Institute of Rural Health, Pocatello, Idaho www.isu.edu/departments/irh/IBAPP/index.shtml

15. McConaghy, T. Using Second Life for Knowledge Transfer and Collaboration. International Workshop on Managing Knowledge for Space Missions. 2007. NASA. Pasadena, CA

http://km.nasa.gov/home/event_KMJuly2007_detail.html

16. Centers for Disease Control. 2008. About CDC Second Life. www.cdc.gov/about/stateofcdc/everywhere/secondLife.htm 
17. Jennings, $\mathrm{N}$ and Collins, C. 2008. Virtual or Virtual U: Educational Institutions in Second Life. International Journal of Social Sciences. Vol 2, Number 3. 